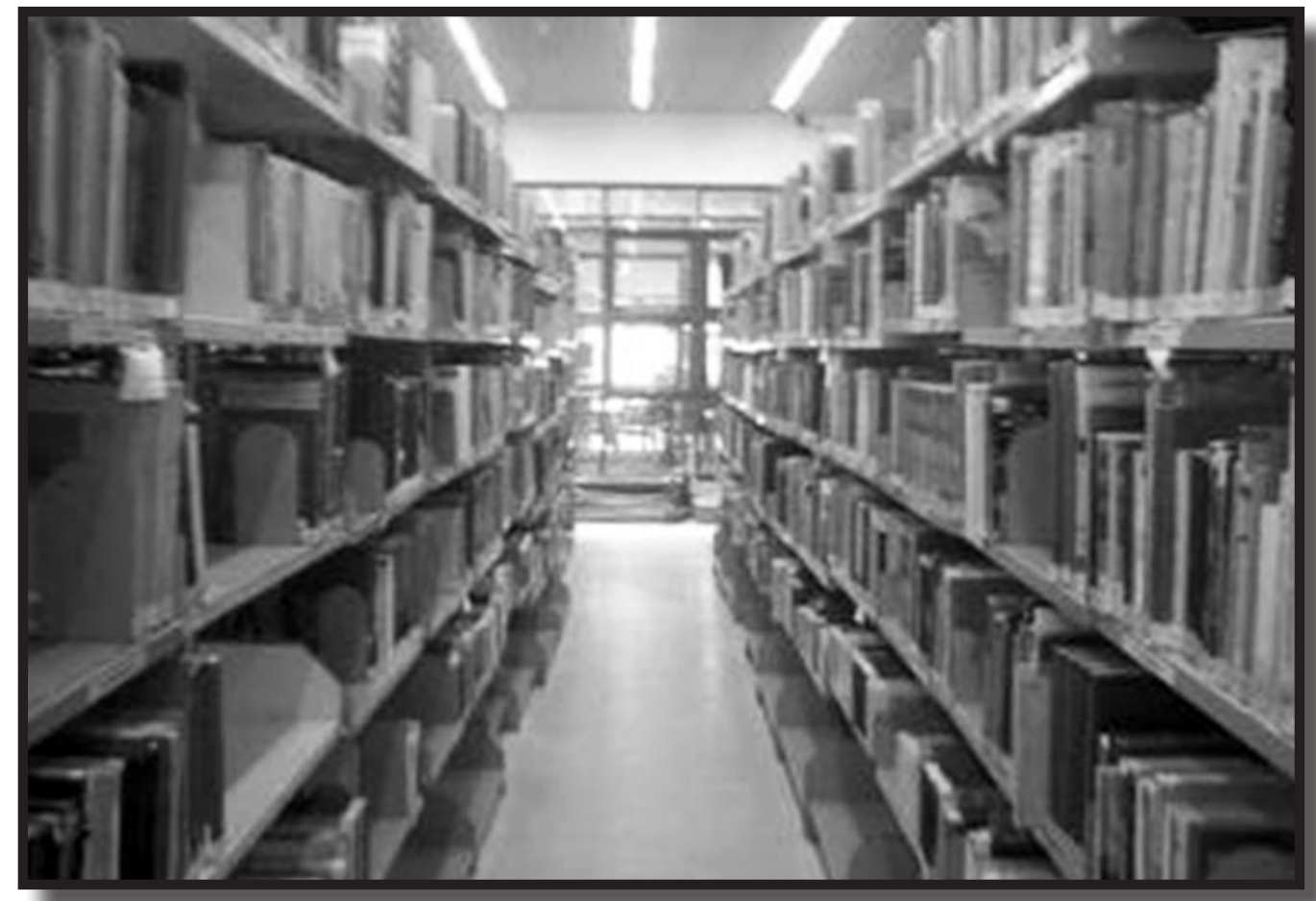

Fonte: Cláudia Brandão (2012), attos@vetorial.net 


\title{
Quando Foto-Graphias (Re)Apresentam Significações Míticas do Imaginário
}

\author{
Cláudia Mariza Mattos Brandão
}

Doutora em Educação pela Universidade Federal de Pelotas (UFPel, RS). Professora do Centro de Artes/ Artes Visuais - Licenciatura, UFPel (Pelotas, RS). Coordenadora do PhotoGraphein - Núcleo de Pesquisa em Fotografia e Educação (UFPel/CNPq), pesquisadora do GEPIEM - Grupo de Estudos e Pesquisas sobre Imaginário, Educação e Memória (UFPel/CNPq).

\begin{abstract}
RESUMO
O artigo tem por objetivo discutir as relações entre a imagem fotográfica e a manifestação do pensamento simbólico, problematizando a linguagem fotográfica como mediadora no processo de compreensão das relações sistêmicas do homem com o meio, apresentando a photoanálise como uma metodologia do Imaginário. Com cunho sócio-fenomenológico, os estudos são norteados pelas ideias de Gilbert Durand, apresentando a foto-graphia como uma instância da imagem que dá visibilidade a emanações arquetípicas materializadas como esquemas simbólicos que remetem ao trajeto antropológico do ser, dando visibilidade aos imaginários fundantes dos sujeitos/fotógrafos, e ampliando os referenciais epistemológicos e metodológicos acerca da fotografia e suas práticas no âmbito das pesquisas acadêmicas.

Palavras-chave: Educação. Fotografia. Imaginário.
\end{abstract}

\section{Abstract}

The article aims to discuss the relationship between the photographic image and the manifestation of symbolic thinking, questioning photographic language as a mediator in the process of understanding the systemic relations of man with the environment, presenting the photoanalysis as a methodology of the Imaginary. With socio-phenomenological studies guided by the ideas of Gilbert Durand, featuring photo-graphia as an instance of the image that gives visibility to archetypal emanations materialized as symbolic schemes that lead to the path of the anthropological being, giving visibility to the founding of the imaginary subjects/photographers, and expanding the epistemological and methodological references about photography and its practices in the context of academic research.

Keywords: Education. Photography. Imaginary. 


\section{Introdução}

É possível dizer que o século $X X I$ traz algumas marcas singulares, assim como a tirania da eficiência, do máximo desempenho, da lógica das novas tecnologias, do mercado e do consumo. Essas características são reforçadas pela importância e centralidade diferenciadas que as imagens, em especial as fotográficas, assumiram no cotidiano das sociedades ocidentais. Esse fato se deve não apenas à quantidade e diversidade de imagens a que cada indivíduo acede no seu dia-adia, mas também aos diversos fins para os quais as mesmas são utilizadas. Percebese, portanto, a necessidade de estarmos atentos às pequenas figuras que povoam 0 cotidiano para conquistarmos o presente. Isso, na compreensão de que com a explosão da "civilização da imagem", a produção obsessiva das imagens distrai e banaliza intenções ocultas, obliterando a nossa percepção daquilo que nos constitui como sujeitos unos.

No contexto dessas relações, da "anestesia da criatividade imaginária" problematizada por Durand (2000, p. 36), a imagem fotográfica encontra-se presente e plenamente integrada em praticamente todas as esferas da vida em sociedade, desde as que permeiam o espaço de circulação, em especial o urbano, assim como as que pertencem à documentação pessoal de cada pessoa. Tal conjuntura nos convoca a refletir sobre a fotografia como um recurso de representação das pessoas e dos seus percursos (auto)biográficos, e, principalmente, de criação e acumulação de conhecimentos produzidos sobre os sujeitos/fotógrafos e seus imaginários.

Há muito tempo o imaginário deixou de ser fruto de uma percepção direta da realidade. Hoje, como nunca, ele se constrói através de uma visualização incessante das representações da realidade produzidas pelas imagens técnicas. $\mathrm{Na}$ análise desta situação é preciso considerar a existência de um campo de intercâmbio entre as imagens e os espectadores, constituído por estímulos e respostas. Assim se configura um "campo de jogo" estabelecido através da capacidade que temos de distanciamento perspectivo em relação ao meio, que permite a captação das realidades e a fundação da vida cultural através da ação criativa (QUINTÁS, 1992).

$E$ no que diz respeito às relações entre Fotografia, Imaginário e Educação algumas questões merecem a nossa atenção, em especial as relativas à abordagem antropológica da fotografia e ao estudo de sua dimensão simbólica como manifestação dos imaginários dos sujeitos/fotógrafos. A aproximação de tais relações é bastante profícua e, associadas a uma perspectiva sociológica, elas produzem novas demandas no que tange à análise do caráter simbólico manifestado pelas imagens.

Nessa perspectiva, a fotografia é interpretada como resultado de ações sociais de produção de sentido, simbólicas, pautadas em códigos estabelecidos pela técnica e pelos imaginários arquetípicos acerca da temática abordada. Com isso quero destacar a fotografia como uma mensagem metafórica que veicula um significado organizado, segundo as regras da produção de sentido de uma linguagem não verbal, mas, também, em acordo com uma relação antropológica. Isso, pois a representação final é sempre uma escolha realizada num conjunto de escolhas possíveis, permitindo a análise de mentalidades e comportamentos que remetem ao trajeto antropológico da humanidade.

Em síntese, essas são algumas questões 
que me acompanham há algum tempo, e que fundamentam a minha tese de doutorado defendida em 14 de maio de 2012. E muito disso se deve a minha relação particular com a fotografia, que me permitiu desde a infância focar o olhar nos detalhes do mundo ao redor, instigando-me a descobrir os meandros da "realidade" que a imagem fotográfica apresenta.

Este artigo tem por objetivo refletir sobre os conhecimentos produzidos na tese de doutoramento em Educação, "Entre photos, graphias, imaginários e memórias: a (re) invenção do ser professor" (BRANDÃO, 2012), desenvolvida junto ao Programa de Pós-Graduação da Faculdade de Educação, da Universidade Federal de Pelotas (Pelotas, RS), tendo como base estudos realizados no Grupo de Estudos e Pesquisas sobre Imaginário, Educação e Memória (GEPIEM/ PPGE/UFPel/CNPq), sob a orientação da Prof $^{a}$ Dr $^{\text {a }}$ Lúcia Maria Vaz Peres.

Trata-se de uma investigação de natureza qualitativa, com cunho sócio-fenomenológico, norteada pelos princípios da metodologia de convergências de Gilbert Durand, na qual a linguagem fotográfica está caracterizada como um exercício de introspecção ativador da imaginação criadora, assim como propõe Gaston Bachelard (1993). Nela, a foto-graphia é apresentada como uma instância fotográfica que dá visibilidade a emanações arquetípicas materializadas como esquemas simbólicos que remetem ao trajeto antropológico do ser.

Tal reflexão me levou à compreensão de que fotografias, acima de tudo, resultam de um ponto de vista particular sobre o objeto registrado. E me proponho aqui a discutir acerca da "fala silenciosa" e perturbadora dos símbolos, identificando a imagem fotográfica como uma intimação simbólica que estimula a reflexão e o devaneio, e, neste caso, definitiva para o meu desenvolvimento e afirmação como uma pesquisadora do imaginário.

Foto-graphias do Imaginário: emanações antropológicas

Como procurei esclarecer na introdução, neste texto discuto a imagem fotográfica como fruto de um processo amplificador de consciência e interpretação do real, que, embora em sua geração seja mediada pela técnica, não admite simplificações conceituais ou generalizações dedutivas. Ao contrário, estou considerando a carga simbólica que dela emerge, pois mais do que (re) apresentar a aparência mundana das coisas, ela expõe a intuição do sujeito fotógrafo e os atravessamentos arquetípicos que nos (re)colocam no trajeto antropológico do ser.

E por esse motivo utilizo em minhas pesquisas a designação foto-graphia, para enfatizar a imagem fotográfica como fruto do exercício do pensamento simbólico, referenciando a capacidade da fotografia de inscrever e grafar depoimentos pessoais sobre o mundo. Considero que a foto-graphia é uma instância da imagem fotográfica que dá visibilidade a esquemas simbólicos que repousam no Imaginário.

Privilegio o sentido de imaginário derivado de Gilbert Durand (2000), segundo o qual o Imaginário resulta do conjunto formado pelo percebido e o herdado, com base no domínio arquetipal. Portanto, ele pode ser considerado um substrato simbólico de ampla natureza que admite a imagem fotográfica como parte integradora do "Museu do Imaginário". Ele floresce das linguagens verbais e não verbais que nos possibilitam a leitura de um mundo. Através do imaginário é possível revelar e 
interpretar as modalidades de atuação e compreensão do ser no mundo, instaurando as diferentes formas de sentir, pensar e agir, como um canal privilegiado das relações do sapiens com o mundo e consigo mesmo. Isso acontece através da troca incessante entre as pulsões subjetivas e as intimações objetivas, do meio cósmico, social e cultural, ou seja, o trajeto antropológico do ser.

As imagens fotográficas são capazes de pré-formar em seu interior uma experiência posterior, ancorada no passado e arraigada no trajeto antropológico do ser. Elas se instituem como construções discursivas que precisam ser lidas, cotejadas e decodificadas, pois o que vemos não é nem a fotografia em sua inércia nem a realidade aprisionada no plano do papel sensível; é, sim, a imagem fotográfica traduzida nos termos de nossa própria experiência. São imagens que se encontram em algum lugar entre as percepções, entre o que lembramos e o que aprendemos, entre o vocabulário comum e um feito por arquétipos ancestrais.

Se analisarmos a questão na perspectiva Junguiana, é possível considerar a fotographia como resultante de ideias e forças primeiras (psíquicas e sociais) que mobilizam formas de agir, viver e sentir, e que podem ser movimentadas pelas demandas do meio. Trata-se, portanto, de construções discursivas entendidas como emanações de experiências passadas, que inscrevem significações para além das aparências. Sendo assim, elas direcionam seus questionamentos para um plano mais amplo da cultura, ampliando os sentidos daquilo que vemos.

O potencial expressivo da foto-graphia associado às teorias do imaginário possibilita a análise das manifestações arquetípicas que nos constituem sujeitos do mundo. Os estudos sobre o imaginário permitem desvendar os conceitos-chaves das representações do Universo, articulando o que é "próprio do homem" e o que brota da nossa faculdade de simbolização, ou seja, do próprio imaginário. E para Durand (2000, p. 36) o imaginário se "define como a incontornável re-apresentação, a faculdade de simbolização, de onde todos os medos, todas as esperanças e seus frutos culturais jorram continuamente, desde um milhão e meio de anos, que o homo erectus apareceu na terra".

Da pesquisa desenvolvida ao longo dos últimos quatro anos retiro subsídios para apresentar as questões que me permitem defender a foto-graphia como uma construção discursiva sobre o mundo, um registro sociológico, antropológico e psicológico, que tem a capacidade de manifestar símbolos introjetados, dando visibilidade aos imaginários fundantes dos sujeitos/fotógrafos. Para tanto, discuto as relações entre as imagens fotográficas e a manifestação do pensamento simbólico, como uma possibilidade para a identificação de indícios subjetivos sobre o mundo ao redor, apresentando, também, a photoanálise como uma metodologia do imaginário.

A temática abordada tem a fotografia como campo empírico e também como um recurso que possibilita a análise dos múltiplos sentidos que movem o universo das representações, consideradas por Durand (1998) como presentificações das heranças arquetípicas. E para que eu possa demonstrar as teorias desenvolvidas na tese, utilizo como exemplos algumas foto-graphias/ dados produzidos por professores formados e em formação, sujeitos da pesquisa, que manifestam/simbolizam suas ideias acerca da docência, do ser professor.

$\mathrm{Na}$ intenção de dar visibilidade a outros modos de dizer, que fogem da esfera do verbal, instiguei os sujeitos da pesquisa a 
criarem suas foto-graphias como respostas à provocação: completem a frase "Ser professor é..." com fotografias! Logo, as "respostas" foram concebidas como metáforas visuais, manifestando conhecimentos indiretos, não objetivos, sobre o universo da docência. Portanto, tais imagens representam uma abertura em direção a novos espaços de significação, nos quais elas existem como atribuição de sentido, e frutificam de um predicado inesperado, configurando o que Paul Ricoeur (2005) denomina "metáfora viva".

As foto-graphias resultam de práticas comunicativas e do exercício do pensamento simbólico, possibilitando adentrarmos no universo mítico do pensamento humano. No caso do tema investigado na tese, a análise das correspondências arquetípicas entre os discursos imagéticos remetem a alguns dos mitos diretores do mundo da docência. Nesse contexto, como pretende Bachelard (1993), a foto-graphia apresenta-se como uma construção discursiva no âmbito estético da racionalidade e um movimento linguístico criador, ritualístico, capaz de dar vida aos mitos.

Desde a Antiguidade o mito inventa simbolicamente uma compreensão das coisas, estabelecendo uma ordem e um sentido ao mundo dos fenômenos. Portanto, o estudo sobre os mitos encaminha a compreensão sobre as relações entre os seres humanos e o mundo, ou o mundo e os seres humanos, como vestígios que repousam em nós. E nesse universo, a foto-graphia permite a identificação de símbolos comuns que remetem a um mesmo significado e determinam comportamentos. Refiro-me, especialmente, aos fundamentos míticos e paradigmáticos que norteiam os pensamentos acerca da docência, do ser professor.
Em busca de manifestações do universo mítico que nos habita: sobre as possibilidades da photoanálise

A proposta para a elaboração de metáforas visuais, como frutos de pensamentos e compreensões sobre o mundo, articula a imagem fotográfica à cognição humana. Na perspectiva dos estudos do imaginário, refiro-me a uma fenomenologia do olhar que estimula a capacidade humana de simbolização, apreendendo a foto-graphia como uma linguagem baseada numa heurística que supõe o imaginário não como uma fantasia a ser combatida, mas, sim, como o nascedouro da realização humana.

A opção particular de discutir a fotografia e o imaginário como reveladores dos universos simbólicos docentes, permitiu-me a abordagem de diferentes re-apresentações e presentificações sobre a docência, problematizando a construção indireta do conhecimento que o universo simbólico proporciona. E para tanto, parti da minha própria experiência como docente, cujas práticas desenvolvidas expõem a riqueza interpretativa de abordagens pedagógicas construídas a partir do observar/manipular/ produzir imagens fotográficas como fontes instigadoras da imaginação e restauradoras da memória.

Para a análise dos conteúdos simbólicos manifestados pelas foto-graphias foi necessário o desenvolvimento de uma metodologia particular, a photoanálise. Diferente do método analógico, ela é um método pragmático que apresenta constelações de imagens estruturadas por um isomorfismo de símbolos convergentes, e que estruturei em três movimentos. Ela é inspirada nos princípios estabelecidos por Gilbert Durand (2002) para metodologias de convergência, e norteada por um princípio 
que mais sugere do que delimita com precisão.

Figura 1- Montagem fotográfica
E para pormenorizar as ações desta etapa da Photoanálise sinto a necessidade de explicitar alguns conceitos que utilizo, com base nas ideias exploradas por Durand (2000, 2002).

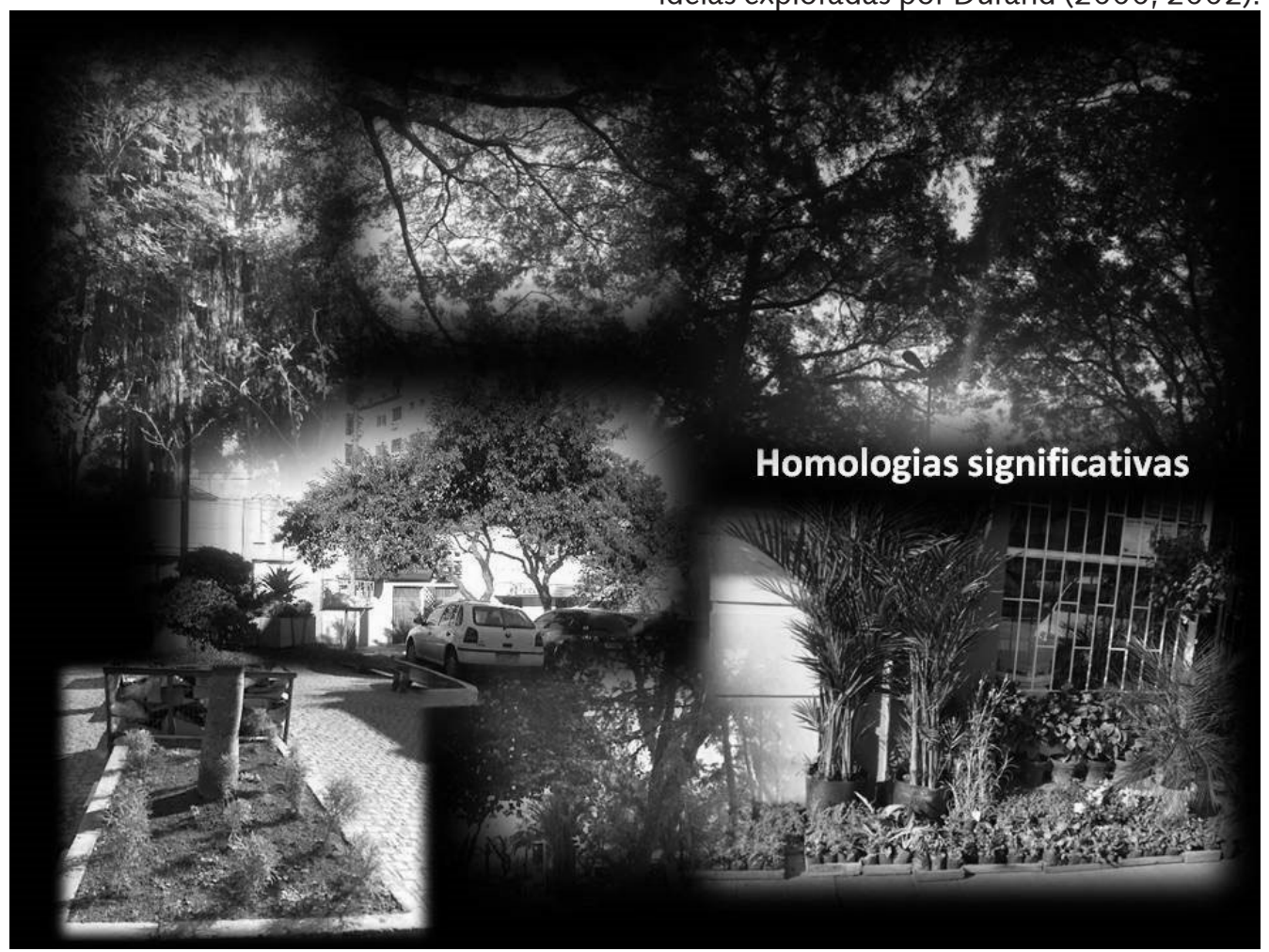

Fonte: Cláudia Brandão (2012).

Do "10 Movimento" consta o levantamento dos símbolos que se repetem de modo significativo nas foto-graphias resultantes das práticas de pesquisa, ou seja, as sincronias míticas dos discursos visuais metafóricos. Para a determinação dos núcleos simbólicos mais pregnantes analisei as homologias significativas dos símbolos manifestados nas imagens. E trago como exemplo um dos conjuntos mais representativos, identificado no banco de dados da tese. Trata-se do núcleo simbólico LUZ SOLAR (Figura 1), a metáfora mais utilizada pelos sujeitos da pesquisa para sintetizar o ser professor.

Identificados os núcleos simbólicos pregnantes, passamos para o "2 Movimento".
De acordo com o autor, o schème é o "presentificador" dos gestos e das pulsões inconscientes, que, diferente de relacionar a imagem ao conceito, une os gestos inconscientes sensório-motores, as dominantes reflexas e as representações. Isso dá à imagem fotográfica mais uma característica, a de dar visibilidade aos schèmes, que formam o esqueleto dinâmico da imaginação.

Se o imaginário origina-se da corporeidade dos schèmes, estes, por sua vez, induzem às imagens arquetípicas. $O$ arquétipo é um intermediário entre os schèmes subjetivos e as imagens fornecidas pelo ambiente perceptivo, estruturando uma zona matricial das ideias na qual temos o comprometimento pragmático do arquétipo em relação a um determinado 
contexto histórico e epistemológico. Ou seja, os arquétipos formam estruturas simbólicas que engendram relações entre o imaginário e os processos racionais, e nessa perspectiva as ideias não possuem primazia sobre as imagens, como a nossa ciência iconoclasta muitas vezes ainda defende.

Nesse contexto, os Mitos são entendidos como sistemas dinâmicos de símbolos, arquétipos e schèmes, que tendem a comporem-se em narrativa, pois, de acordo com o pensamento de Durand (2002), os mitos são esboços de racionalização, nos quais os símbolos se resolvem em palavras e os arquétipos em ideias. $O$ mito explicita um schème ou um grupo de schèmes e serve de modelo arquetípico e justificação para todas as ações e criações.
Assim sendo, é possível afirmar que o imaginário é formado por um sistema de estruturas capaz de designar os esquemas originais que agrupam certos protocolos normativos das representações imaginárias, ativadas por um amplo conjunto de arquétipos que repousam no inconsciente coletivo desde os primórdios da humanidade e que reproduzem constantemente a cultura. E isso vem ao encontro das ideias de Cassirer (2005) no entendimento de que pregnância simbólica diz respeito às vivências perceptivas, sensíveis, que trazem imbricadas intuições e significados não intuitivos, que na presente análise ganham representação concreta através das imagens fotográficas.

Dentre as imagens analisadas destacam-se quinze núcleos arquetípicos

Figura 2- Montagem fotográfica.

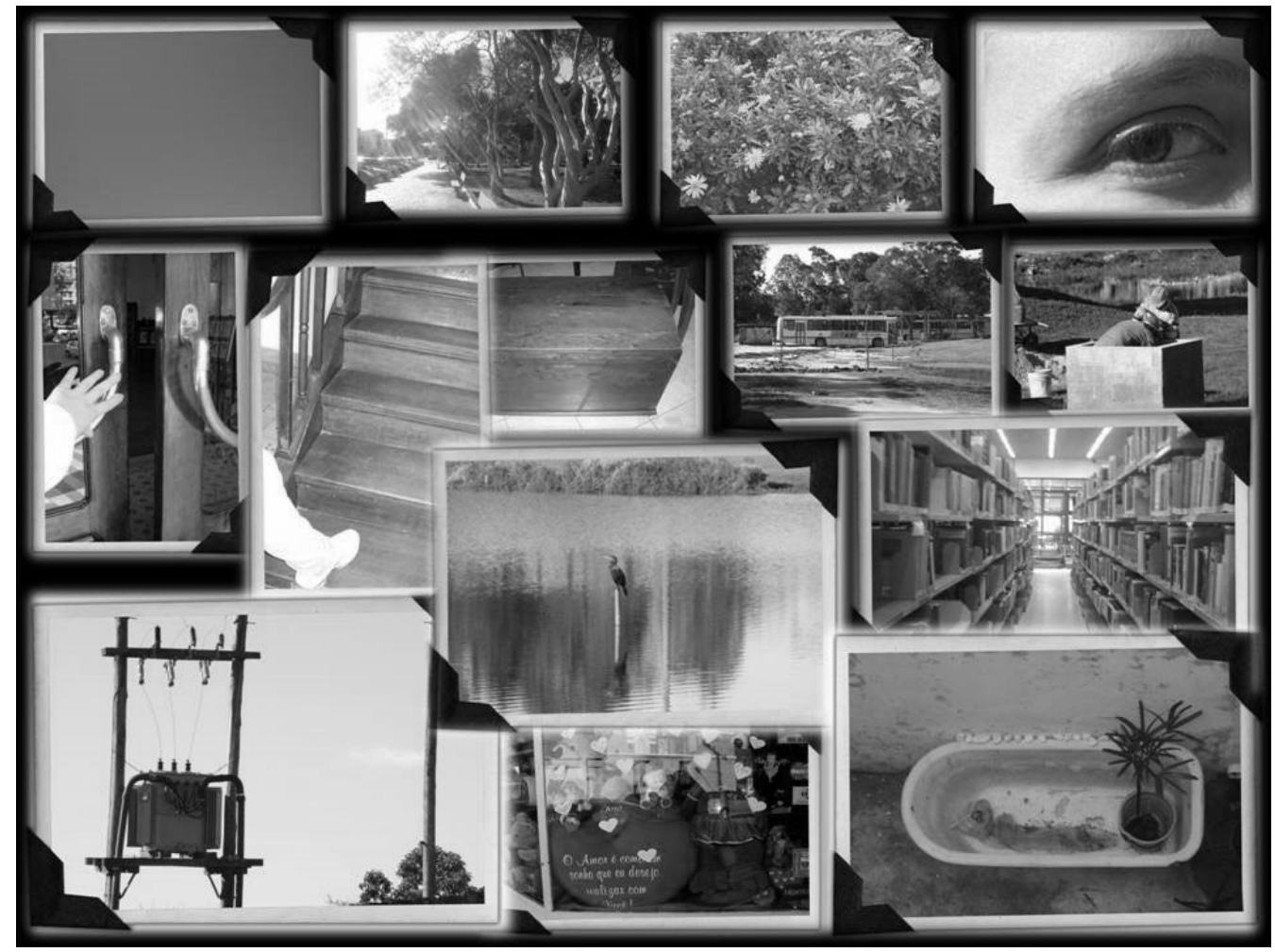

Fonte: Cláudia Brandão (2012). 
significativos. Além da LUZ/SOL (Figura 1), temos CÉU, JARDIM/FLOR, OLHO/ OLHAR, GUIA/PRINCÍPIO, ESCADA, ARCA, MENSAGEIRO/VIAJANTE, CONSTRUÇÃO, TRANSFORMADOR, REFLEXO, AMOR/ CORAÇÃO, BIBLIOTECA, COLEÇÃO e OBRA DE ARTE (Figura 2).

A apreciação do conjunto acima caracterizado nos permite discutir acerca das diferentes lições dos mitos identificados (diacronia) e das correlações entre eles. E esse é o mote do " $3{ }^{\circ}$ Movimento" da photoanálise, numa comprovação das raízes míticas que repousam silenciosas nos sujeitos/ fotógrafos, influenciando as mentalidades e os comportamentos.

A análise realizada para a tese apresentou três grandes mitos diretores para o mundo da docência, revelando as múltiplas facetas imbricadas nas figuras de Prometeu, Hermes e Narciso:

- PROMETEU-como uma manifestação dos sete (7) mitemas CÉU, LUZ/SOL, JARDIM/FLOR, OLHO/OLHAR, GUIA/PRINCÍPIO, ESCADA, ARCA;

- HERMES - cujas características manifestam-se através de três (3) mitemas MENSAGEIRO/ VIAJANTE, CONSTRUÇÃO $\mathrm{e}$ TRANSFORMADOR;

- NARCISO - cuja presença é reforçada pelos mitemas REFLEXO, AMOR/ CORAÇÃO, BIBLIOTECA, COLEÇÃO e OBRA DE ARTE.

Os três mitos gregos fundadores que em acordo com a metodologia proposta se anunciam como representantes do mundo da docência: Prometeu, Hermes e Narciso, são também abordados como "males", pois os sintomas representados por esses mitos são como pontos de obsessão, implicando em sofrimento para o homem. Por exemplo, ao mito está associado o "complexo de Prometeu", que diz respeito a pessoas que acreditam saber mais do que os outros. Portanto, a figura do ser professor integrada a esse mito nos apresenta um dos possíveis males da docência, ou seja, aquele que se coloca num patamar superior, acreditando que detém todo o conhecimento.

No caso do "Professor Narciso" (Figura 3) temos o mitema OBRA DE ARTE compondo com os demais, COLECIONADOR, BIBLIOTECA, AMOR/CORAÇÃO e REFLEXO, uma convergência simbólica que reforça o mal de Narciso. E isso pode ser analisado sob uma ótica positiva, acenando para a possibilidade de crescimento que a partilha do conhecimento, num ato de iluminação, oferece. Sob outro viés, a proposta de crescimento e passagem que as metáforas visuais nos oferecem está centrada num olhar soberano sobre o mundo, como se um eu, solitário, fosse capaz por si só de determinar transformações em outrem. Temos, portanto, também a caracterização de um ego individualista na busca de seu próprio reflexo, que, assim como Narciso, pode mergulhar no lago apaixonado pela própria beleza. 
Figura 3 - Montagem fotográfica

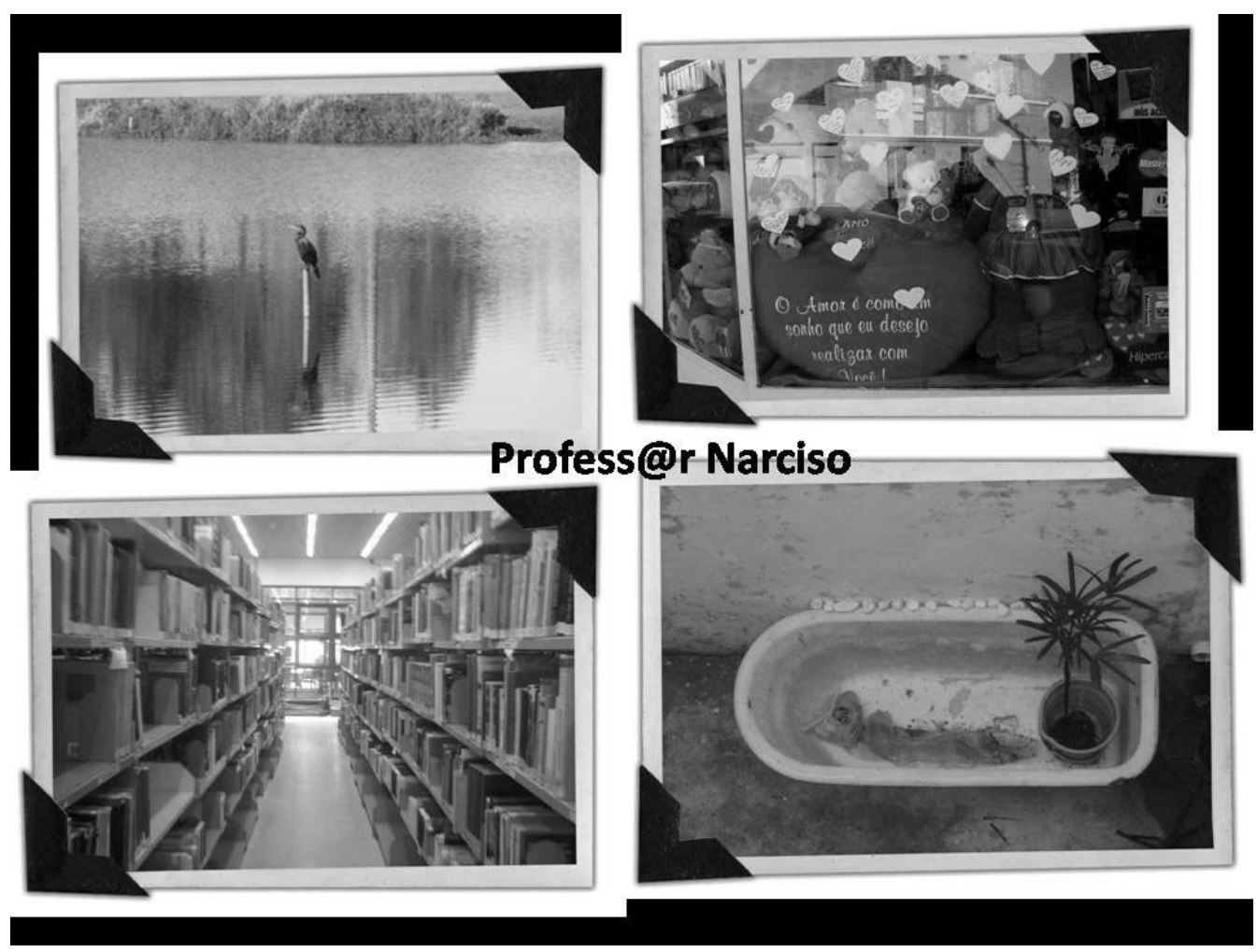

Fonte: Cláudia Brandão (2012).

Perambulando por trajetos imaginados, das foto-graphias aos mitos

Busquei ao longo deste texto demonstrar que o exercício da foto-graphia conduz à partilha dos múltiplos significados atribuídos pelos sujeitos/fotógrafos, sem a intencionalidade de confirmar ou corrigir teorias. Através de tal prática é possível manifestar conhecimentos que não são objetivos, diretos, desafiando consensos e instaurando múltiplos posicionamentos.

Temos aí a imagem fotográfica situada no ponto de convergência entre o que (re)apresenta ao olhar e o que simboliza enquanto signo atrelado a uma subjetividade. Tais imagens alentam o processo de compreensão, interpretação e elaboração de significados que inevitavelmente reúnem

as questões da verdade objetiva e os planos subjetivos de realidade. É o que Durand chama de "conhecimento indireto", fruto do exercício do pensamento ético e estético, nos mostrando que as coisas não são tão evidentes por si mesmas quanto muitas vezes acreditamos que seja.

Nesse contexto, a photoanálise, através da "fala silenciosa" dos símbolos, permitenos reencontrar nos mitos os seus princípios oníricos, não os ecos de um passado longínquo. As imagens apresentadas resultam do devaneio poético de "sonhadores da chama da vela" (BACHELARD, 1989), fruto da contemplação em profundidade e da elaboração metafórica do pensamento, como resultado da síntese entre a interioridade e a realidade exterior, viabilizando uma "abertura" aos mundos arcaicos.

Os movimentos da photoanálise 
envolvem a "verticalização" significante numa retomada de temas primitivos acessados pela prática da foto-graphia. Com a expansão do espaço íntimo dos sujeitos/fotógrafos para o espaço da representação, temos um espaço duplicado através da consciência da própria existência. Analisar as imagens a partir da instância simbólica possibilita a apresentação e o debate de aspectos da realidade sem restringi-la às raízes históricas e sociais.

A imagem fotográfica, principalmente na atualidade, permite obtermos infinitos efeitos que reconstroem o real a todo instante. No entanto, empregada como materialização de metáforas visuais vivas, como eu proponho, elas ampliam a retórica dos discursos visuais. E isso se deve à sua caracterização como schème, o que acentua a função esquematizante das imagens, revitalizando os mecanismos da linguagem fotográfica.

Os mitos, essas narrativas que se traduzem através de símbolos (manifestação) e arquétipos (ideia), são como que pontes entre as cavernas subterrâneas dos egos e a luminosidade que se anuncia em suas entradas. Nessa mescla de luz e sombra manifestam-se as redes de convergência simbólica. Elas nos possibilitam participar do jogo estabelecido entre os temas míticos, seus personagens e cenários, e a racionalização dos discursos. Ao mesmo tempo, ingênuo e complexo, transparente e opaco, o jogo expõe as relações entre as dominantes reflexas e as representações.

Posicionada como uma pesquisadora do imaginário, eu procurei em minhas investigações uma reflexão metodológica mais alargada, numa démarche hermenêutica de natureza sócio-fenomenológica e crítica. E os conhecimentos que dessas práticas emergiram são extremamente sensíveis ao caráter polissêmico da existência dos seres humanos e do dinamismo que aí se impõe. Portanto, frente à complexidade do caráter subjetivo de meus dados, busquei uma reflexão metodológica mais alargada, que não poderia ser uma prática automática, mas, acima de tudo, problemática. Desse modo, acredito que os significados, social e culturalmente construídos, não se tornam "destroços diurnos" de uma estatística realizada para a conclusão da pesquisa. Ao contrário, tais elementos são trazidos para o cenário ativo da construção do saber com tudo aquilo que lhe é próprio.

Analisando os meus trajetos ao longo da pesquisa, vejo que atuo assim como um COLECIONADOR, alguém que recolhe os restos esquecidos ou os excessos suprimidos, plenos de contradições, paradoxos, ambiguidades, ambivalências, assincronias, e tudo o mais que diga respeito às minhas próprias incertezas. Tudo isso para depois tentar recompô-los em narrativa, e falar do arcaico que em mim também habita. Reconheço que a investigação realizada para a tese nada mais é do que um caminhar para si, pois "é nessa reversão que o pesquisador encontra os meios de efetuar uma pesquisa que seja formadora e transformadora". (JOSSO, 2010, p. 31).

Caracterizada como schème, um símbolo motor, a imagem apresenta-se como uma encarnação do significado através de um significante, a foto-graphia, passível de ser desvelada pela photoanálise, uma metodologia do Imaginário. Portanto, temos aqui a imagem favorecendo o reconhecimento dos substratos das atitudes sociais, reflexos de mentalidades e comportamentos, mas, principalmente, confirmada como um modo de re-apresentar e presentificar os arquétipos, revelando as raízes arcaicas que nos posicionam no trajeto antropológico do ser. 


\section{Referências}

BACHELARD, Gaston. A chama de uma vela.

Rio de Janeiro: Ed. Bertrand, 1989.

BACHELARD, Gaston. A água e os sonhos. São Paulo: Martins Fontes, 1989.

BACHELARD, Gaston. A poética do espaço. São Paulo: Martins Fontes, 1993.

BRANDÃO, Cláudia Mariza Mattos. Entre photos, graphias, imaginários e memórias: a (re)invenção do ser professor. 2012. $154 \mathrm{f}$. Tese (Doutorado em Educação) Universidade Federal de Pelotas, Pelotas, 2012.

CASSIRER, Ernst. Ensaio sobre o homem: introdução a uma filosofia da cultura humana. São Paulo: Martins Fontes, 2005.

DURAND, Gilbert. O imaginário: ensaio acerca das ciências e da filosofia da imagem. Rio de Janeiro, DIFEL, 1998.

DURAND, Gilbert. A imaginação simbólica. Lisboa, Portugal: Edições 70, 2000.

DURAND, Gilbert. As estruturas antropológicas do imaginário. São Paulo: Martins Fontes, 2002.

JOSSO, Marie-Christine. Caminhar para si. Porto Alegre: EdiPUCRS, 2010.

QUINTÁS, Alfonso López. Estética. Petrópolis, RJ: Vozes, 1992.

RICOEUR, Paul. A metáfora viva. 2. ed. São Paulo: Edições Loyola, 2005. 